\title{
Sensitization of Women Fish Processors on the Benefits of Birth Control Measures in the Coastal Areas of Lagos State, Nigeria
}

\author{
Akinsola $00^{1}$, Oyediran W $0^{* 2}$, Omoare A $\mathbf{M}^{3}$, Badaru, $\mathrm{R} \mathrm{A}^{1}$, Onabajo A $\mathbf{0}^{2}$, Fasasi R $\mathrm{B}^{2}$ and Adeyanju Y T \\ ${ }^{1}$ Department of Home Economics Education, Federal College of Education, Nigeria.
}

${ }^{2}$ Department of Agricultural Extension and Rural Development, Federal University of Agriculture, Nigeria.

${ }^{3}$ Department of Agricultural Education, Federal College of Education, Nigeria.

Submission: May 25, 2018; Published: July 31, 2018

Corresponding author: Oyediran WO, Department of Agricultural Extension and Rural Development, Federal University of Agriculture, Abeokuta, Nigeria, Email: oyediran_wasiu@yahoo.com

\begin{abstract}
In Nigeria, there has been increasing advocacy for birth control measures (BCMs) to checkmate the ever-rising population which has led to youth unemployment, unrest, kidnappings and killings in every part of the country; in many cases, women and children are worst hit by these problems. But, women in the rural areas particularly those in the coastal areas are often not reached by this sensitization programme due to their remote locations. Thus, this study looked at sensitization of women fish processors on the benefits of birth control measures in the Coastal Areas of Lagos State, Nigeria with the aim of identifying the lapses and proffer possible way forward. Three hundred and sixty women fish processors were selected from twelve fishing communities in the study area. Data were collected and analyzed with descriptive statistics and chisquare. Results showed that majority (66.7\%) were in child-bearing age (20-40 years), $84 \%$ were married, and $81 \%$ had basic education. About $74.7 \%$ and $86.7 \%$ were aware of traditional and modern BCMs respectively. Sensitization on benefits of BCMs was through friends, Health Care Providers, radio and television. Chi-square results indicated that sources of information had influence on level of sensitization of birth control measures at $p<0.05$ level of significant. The study hereby recommends that tempo of sensitization on the benefits of BCMs should be continuous in the coastal areas of Lagos State.
\end{abstract}

Keywords: Sensitization; Birth control measures; Benefits; Women; Coastal areas

\section{Introduction}

A common problem ravaging Sub-Saharan African (SSA) countries including Nigeria are the issues of poverty, poor education, food scarcity and high crime rate. In Nigeria, these problems have been linked to increased population with very limited resources. Fertility, mortality and migration are the three factors responsible for population change. High population growth is a big problem and counterproductive to Nigeria which has led to high unemployment and crimes in the country. Birth control could have significant effect on these problems and thus a good policy option for the government. However, birth control practices in Nigeria are still regrettably low resulting to multiple births, high maternal rate and risks of contacting Sexually Transmitted Diseases. Augustine \& Mathias [4] explained that maternal mortality have been noted to be prevalent in SubSaharan Africa and other resource-poor and underdeveloped nations of the world due to unplanned pregnancy and unsafe abortion. Besides, uncontrolled population has pressure on the environment. As the society develops in size and quantity, the demands on resources increase in both intensity and density. This puts pressure on the environment resulting in humaninduced disasters that could lower production. Rural women particularly those in the remote coastal areas of Nigeria are the most affected by these myriads of problems due to limited access to land, credit, health facilities and other rural infrastructure. Whereas studies have shown that women have always been active economic agents; they are active at the home front, in trade, in technical service delivery, agriculture, fisheries and agro allied services, artisanship among other areas of human endeavour [2]. They play pivotal role in sustainable development in rural communities [3], and contribute between $40-65 \%$ of all hours spent in agricultural production and food processing [4]. Women are highly involved in every aspect of fish processing and marketing in the rural areas which contribute to their economic empowerment, food security and poverty reduction [5]. Thus, 
the reproductive health of these women through contraception is very important. Jacoba [6] posited that contraception goes beyond woman's personal well-being; it plays a pivotal role in the financial, physical and emotional health of children and in the end, ensuring women empowerment and assists them to have a predetermined number of children.

Sequel to the above, Nigeria cannot ignore population control to ensure healthy living of her rural women in the coastal areas. Mothers, who mostly bear the brunt of unplanned maternity in terms of damaged health and even death need to be given due consideration. Nigeria according to National Population Commission [7] has one of the highest mortality rates in the world. Since the adoption and use of birth control measures is dependent on the level of awareness and conviction, sensitization of rural women on the benefits of birth control measures therefore need to be given a massive boost to get better results, particularly in the coastal areas. Sensitization on the benefits of birth control measures appears to be closely related to development communication and behavioural change theories. This assumed connection is premised on the fact that motive behind promotion of birth control in many developing countries (including Nigeria) is development-induced. According to Cleland et al. [8], the main motive for birth control was to enhance prospects for socio-economic development by assisting rural women to achieve an effective child spacing. By implication, the underlying reason for birth control (irrespective of theories) is to solve the problem of population-resource imbalance particularly those that has to do with overpopulation and enhances women reproductive health. Besides, sensitization led to awareness which considered as the first phase in behavioural change [9]. Awareness is closely associated with communication. This communication may be verbal or nonverbal. It is assumed that once the respondents are aware of the benefits of birth control on their reproductive health and fish processing activities, they will effect behavioural change action that is reasoned. In other words, women fish processors who are the target of this study is presumed to be rational and that when they understand benefits of birth control measures on their reproductive health, they will rationalize their actions towards adoption of birth control, subject to various factors. In order to provide empirical information that could help in understanding the remote cause of low utilization of birth control measures by the rural women in Nigeria, this study assessed the level of sensitization of birth control measures among women fish processors in the coastal areas of Lagos State, Nigeria.

\section{Specific Objectives are to}

I. Ascertain the socio-economic characteristics of women fish processors in the coastal areas;

II. Assess the level of awareness of various birth control measures available for use in the coastal areas;

III. Examine the level of sensitization on the benefits of birth control measures in the coastal areas;
IV. Identify the various sources of information on benefits of birth control measures in the in the coastal areas.

\section{Hypothesis}

$\mathrm{H}_{01}$ : Sources of information on birth control measures have no significant influence on the level of sensitization in the coastal areas.

\section{Theoretical Concept}

\section{Diffusion of innovations theory}

Diffusion is the process by which an innovation is communicated through certain channels over time among the members of a social system. Diffusion is a special type of communication concerned with the spread of messages that are perceived as new ideas. Diffusion of innovation theory could therefore be used to explain relationship between sensitization, awareness and use of birth control measures. Diffusion of Innovation Theory focuses on how new ideas, concepts, or practices can spread within a community or society or "from one society to another" [10]. Although, the idea of birth control (traditional methods) may not necessary qualify as new thing since evidence suggests its practices from time immemorial, the motive and manner in which it is practiced have changed considerably. The modern birth control measures could however be viewed as innovation. The theory posits that diffusion of innovation (in this case sensitization, awareness and utilization) is a gradual process involving key participants whose adoption tendency is hierarchical in nature. This involves 5-step innovation-decision process which is knowledge, persuasion, decision, implementation and confirmation. Based on time, innovativeness of individuals varies and specifically, the theory identifies and defines five (5) subgroups of individuals in the adoption continuum [11]. The subgroups include innovators, early adopters, early majority, late majority and laggards. Diffusion of innovation theory, as related to birth control measures, means that women fish processors are most likely not to adopt and use birth control practices at first contact with information. According to diffusion of innovations theory, innovators are expected to act as role model that facilitates adoption by other subgroups. In the diffusion of birth control measures, community leaders, women leaders and other stakeholders are target audience while health workers perform facilitating role. The implication of this is that awareness could be made more effective, if opinion leaders and innovators are identified and contacted first. Educational level, socio-economic background (e.g. status of parenthood or guidance), personality, rationality, and resourcefulness, exposure to media and social involvement play important role in the innovativeness of the women fish processors. For instance, people with high level of education are more likely to be among the innovators or early adopters [12]. The relevance of diffusion of innovations theory to health communication and awareness of birth control measures cannot be over-emphasized. 


\section{Health belief model (HBM)}

Health belief model (HBM) intends to provide justification to take up health practice offered or health-related behavioural change proposed or recommended by emphsizing positive trade-offs between benefits of adoption or behavioural change and possible barriers to or cost of the change [12]. Birth control, apart from being development-induced also sought to improve maternal health as an important variable in improving women reproductive health. The HBM according to the National Cancer Institute and National Institutes of Health (2002) was originally intended to explain why people did not participate in programs that could help them diagnose or prevent diseases. Schiavo [12] posited that the "major assumption of this model is that in order to engage in healthy behaviours, intended audiences need to be aware of their risk for severe or life-threatening diseases and perceive that the benefits of behaviour change outweigh potential barriers or other negative aspects of recommended actions". HBM is reputed as one of the first theories developed to explain the process of change in relation to health behaviour and which inspired the development of health education Schiavo [12] highlights key components of HBM as including perceived susceptibility, perceived severity, perceived benefits, perceived barriers, cues to action and self-efficacy. By perceived susceptibility, individual's self-judgement of his/her exposure to risk of contracting a disease or health problem. In the case of birth control, HBM holds that if the targets is aware and believe that birth control could improve her health as well as increase their productivity, barring other variables, they will more likely adopt promoted health practices like birth control. The major contribution of the HBM to the health and development communication field is its emphasis on the importance of knowledge, a necessary but not sufficient step to change. In other words, the model fundamentally assumes that knowledge will bring about change. This model is relevant to communication necessary to create awareness that is effective towards effecting behavioural change because health and developmental communication intend to pass knowledge of benefits of adoption of birth control as besting associated cost in terms of self-control.

\section{Research Methodology}

\section{Description of the study area}

Lagos State was chosen as the study area in this research because of its riverine nature, high fishing activities and commerce. The State was created on May 27 $7^{\text {th }}, 1967$. It has 57 Local Government Areas and was the capital of Nigeria until 1976. It is referred to as the 'centre of excellence'. It is the nation's largest urban centre and economic hub of the country [5]. The state covered a total of $3,939 \mathrm{~km}^{2}$ of land. It spans the Guinea coast of the Atlantic Ocean for over $180 \mathrm{~km}$, from the Republic of Benin on the west to its boundary with Ogun State in the east. It extends approximately from latitude $6^{\circ} 2^{\prime} \mathrm{North}$ to $6^{\circ} 4^{\prime}$ North and from longitude $2^{\circ} 45$ East, and 22 percent of it is $787 \mathrm{~km}^{2}$ land is covered by water.

\section{Sampling technique and sample size}

Population of this study was artisanal women fish processors in the coastal areas of Lagos State, Nigeria. Twelve (12) fishing communities were purposively selected from Far Eastern region of the state for this study. These communities are Ilaje, Eleko, Iberekodo, Orimedu, Awoyaya, Oniyanrin, Afolu, Akodo, Ebute Chief, Epe, Orimedu, and Eredo. Thirty women fish processors were randomly selected from each of the selected fishing communities to obtain a total of 360 respondents as sample size for this study; the women have association regulating their activities and price control. The sample size was achieved through their list and support of women leaders in these communities.

\section{Validity and reliability test}

The instrument used for data collection was validated by the nurses and midwiferies, and experts in the field of agricultural extension, and fisheries. Ambiguous items were removed based on the suggestion of experts. Split-half method was used for the reliability of the research instrument to determine its internal consistency. The coefficient was calculated using split-half method. The result of obtained was 0.82 , indicating that the instrument is reliable for the study.

\section{Measurement of variables}

Age, number of children and fishing experience were measured at ratio level. Educational status, marital status and awareness were measured at nominal level. For the level of awareness, scores between 0-8 are regarded as high awareness while 9-16 are low awareness. The measurement of awareness of BCMs used by Akinsola et al. (2018) was adapted for this study. Sources of information were measured on a 3-point rating scale of Always (3), Occasionally (2), and Not at all (1). Also, sensitization was measured on a 3-point rating scale of Well informed (3), Partially informed (2), and Not informed (1). Descriptive statistics and chi-square were used for the data analysis.

\section{Results and Discussion}

\section{Personal characteristics of women fish processors in the coastal areas}

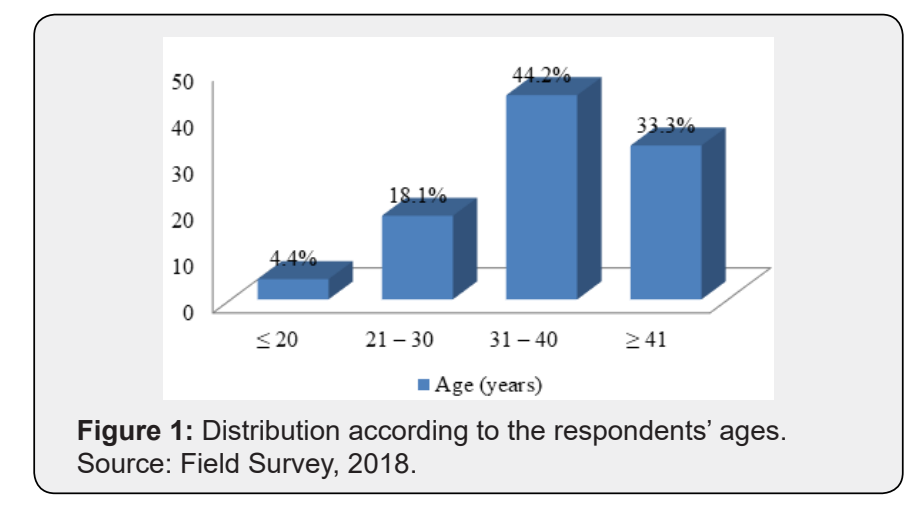

Results in Figure 1 showed that $44.2 \%$ of the respondents were between $31-40$ years of age; $33.3 \%$ were above 41 years 
of age; only few $(4.4 \%)$ were less than 20 years of age. It is an indication that the respondents are relatively young, within economically active and child-bearing age bracket. Findings by Ahmed-Adamu [13], and Sodiya \& Oyediran [14] have shown that most rural women in Nigeria are within this age bracket and they are economically active and in a reproductive stage.

\section{Marital status of the women fish processors}

Result in Figure 2 showed that most (84\%) of the respondents were married while the remaining $16 \%$ were divorced. A previous study by Oyediran et al. [5] on low-cost fish processing technologies had indicated that majority of women fish processors in the coastal areas of Lagos State, Nigeria are married. This is further corroborated by the findings of Omoare et al. [15] and Oyediran et al. [5] that individuals in marriage provide food and clothing to the members of their household. Since majority is married the implication for the study is that women fish processors need to be sensitized on benefits of BCMs so that they can adopt and utilize various methods for child spacing and birth control in the coastal areas.

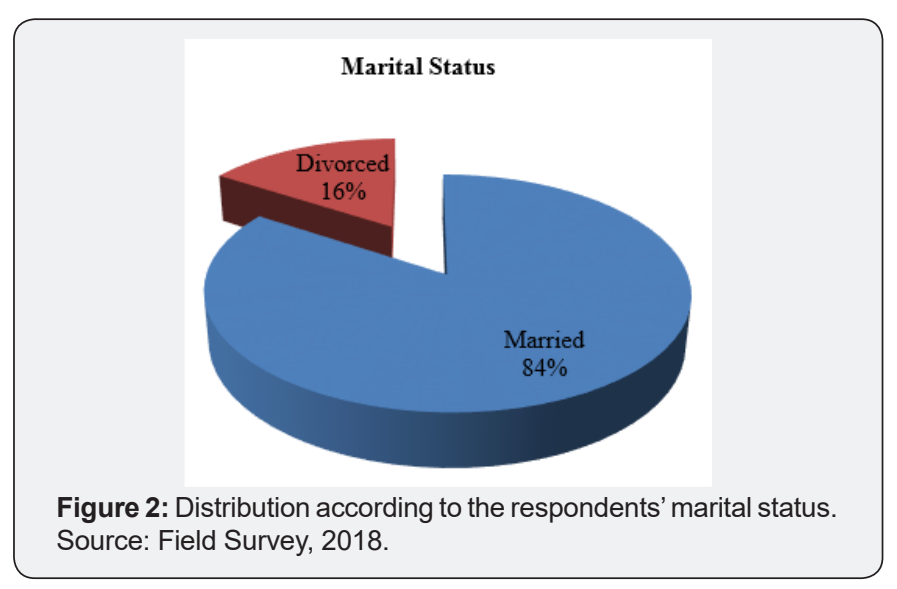

\section{Education of the women fish processors}

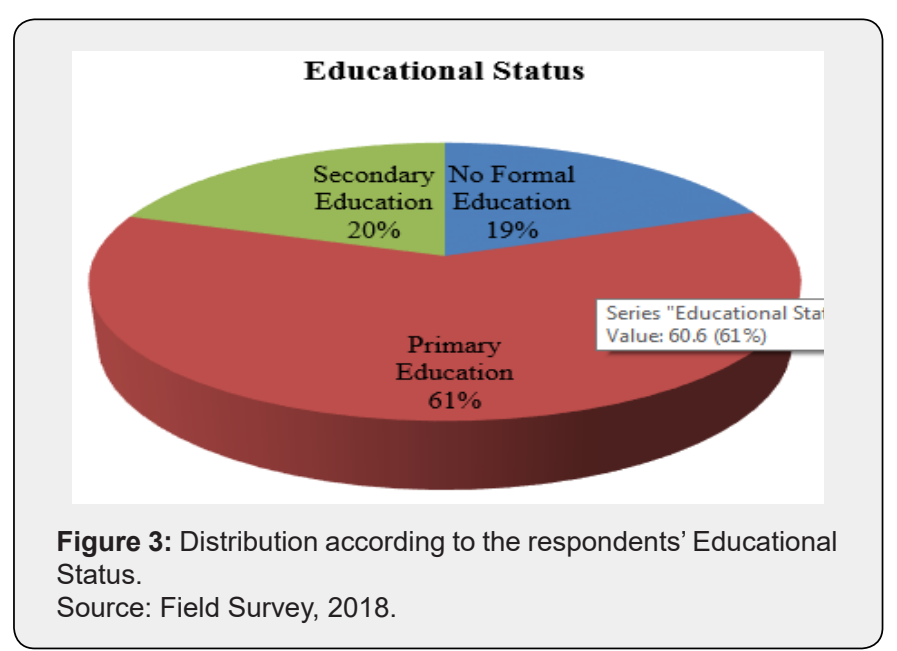

Sixty-one percent of the respondents had primary education; and $20 \%$ had secondary education; but $19 \%$ did not have formal education. Though majority ( $81 \%$ ) of the women fish processors has basic education the literacy level is still very low since none of them attained tertiary education. Education is instrumental to sensitization and could promote the use of birth control measures (BCMs) in the coastal areas. Educated women have been reported to have good knowledge of birth control methods than their non-educated counterparts in the rural areas [16]. The basic education of the women could be harnessed for sensitization programmes and utilization of BCMs in the coastal areas (Figure 3).

\section{Fish processing experience of the women fish proces- sors}

The results revealed that $13.9 \%$ of the respondents had spent less than 10 years in fish processing activities; $29.4 \%$ spent $11-15$ years; $35 \%$ had spent $16-20$ years; and $21.7 \%$ had spent more than 21 years. This is an indication that the women fish processors have been in fish processing activities from their early age. These results are in line with findings of Akinsola et al. (2018). According to Omoare et al. (2015), years of experience play a vital role in artisanal fishing. Experience of the women could be transformed to high productivity if they have good reproductive health through sensitization on BCMs and its use (Figure 4).

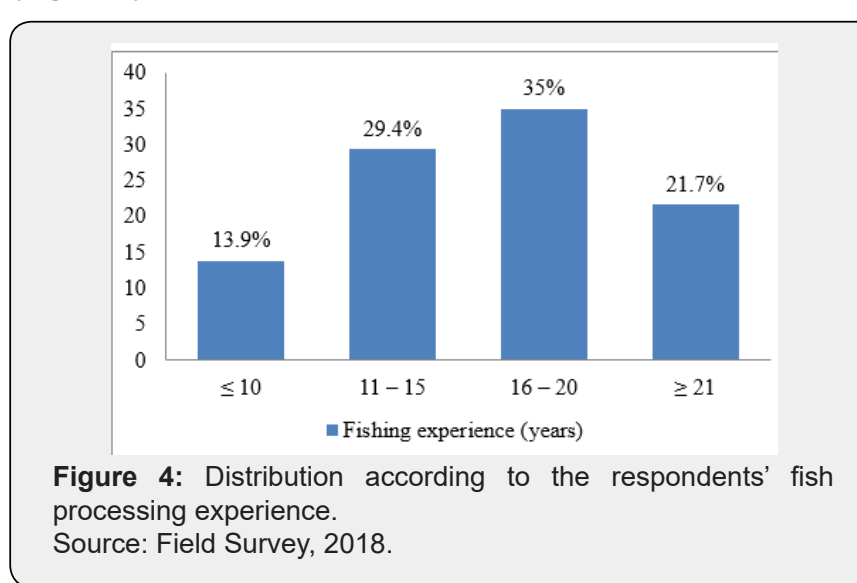

\section{Number of children}

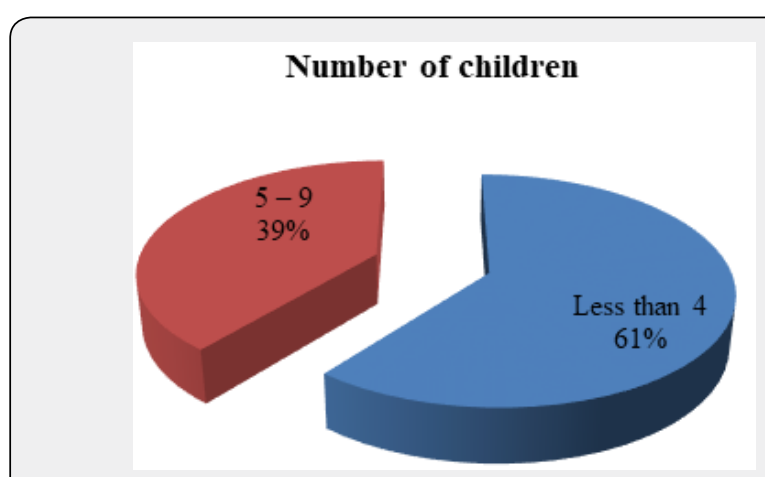

Figure 5: Distribution according to the number of children. Source: Field Survey, 2018.

Also, $61 \%$ of the respondents had less than 4 children in their households whereas 39\% had 5-9 children in their households. This means that majority of women fish processors did not have too many children since having up to 4 children is a common practice in Nigeria. Sensitization on BCMs becomes 
necessary to prevent the women fish processors from having unwanted pregnant and abortion and to be able to take care of their children in terms of providing good food, clothing and quality education for these children. Sonia [17] emphasized that contraception affords women the opportunity to be better parents since women who experience unplanned childbirth are more likely to be depressed, overly subject to sexual and social imperatives thereby engulfed with anxiety (Figure 5).

\section{Level of awareness of various birth control measures available for use in the coastal areas}

The results in Table 1 showed $74.7 \%$ of the respondents were aware of use of waist band (igbadi), $61.4 \%$ were aware of incision (gbere), 58.1\% were aware of concoction (aseje), and 56.9\% were aware of concocted ring (oruka ere) of traditional birth control methods. The high awareness of traditional methods of BCMs is as a result of indigenous knowledge of traditional medicine by the women in the rural areas of Nigeria. In most of the rural areas, health centres are hardly available which made the rural dwellers to increasingly used traditional medicines for treating their health problems. In a similar vein, $86.4 \%$ of the respondents were aware of safe period (rhythm method) and $87.5 \%$ were aware of withdrawal method (coitus interruption) while $33.1 \%$ were aware of Breast Feeding (amenorrhea method) of natural birth control methods. Olugbenga-Bello et al. [18] and Akinsola et al. (2018) high awareness of natural birth control methods but low utilization in the rural communities of Nigeria. Results further revealed that $86.7 \%$ of the respondents were aware of combined oral contraceptives, $90.6 \%$ were aware of injectable contraceptives, $90 \%$ were aware of contraceptives implants, (implanon), 87.8\% were aware of contraceptives ring (nuva ring) and $86.7 \%$ were aware of skin patch of modern birth control measures. Report has shown that awareness of modern birth control measures is very high in Southwest, Nigeria [19]. The high level of awareness could be harnessed for adoption and utilization of birth control measures in the coastal areas of Lagos State, Nigeria. Moreover, 83.4\% of the respondents were aware of copper T shaped IUD (paraGard) whereas only very few (12.1\%) were aware of hormonal IUD (mirena). Similarly, 79.4\% were aware of condoms (male and female) while 10.6\% were aware of Cervical caps of barrier methods of BCMs. Findings of Senbet et al. [20] and Akinsola et al. (2018) revealed that both young and adult women are aware of condom. Sensitization and public enlightenment on birth control measures particularly those with low awareness should be put in place by the medical experts in the coastal areas of Lagos and Nigeria at Large.

Table 1: Awareness of various birth control measures available for use in the coastal areas $(n=360)$.

\begin{tabular}{|c|c|c|}
\hline \multirow{2}{*}{ Types of Birth Control Measures } & \multicolumn{2}{|c|}{ Awareness } \\
\hline & Aware & Not Aware \\
\hline \multicolumn{3}{|c|}{ a. Indigenous control method } \\
\hline Waist Band (igbadi) & $269(74.7)$ & $91(25.3)$ \\
\hline Incision (gbere) & $221(61.4)$ & 139(38.6) \\
\hline Concoction (aseje) & $209(58.1)$ & $151(41.9)$ \\
\hline Concocted ring(oruka ere) & $205(56.9)$ & $155(43.1)$ \\
\hline \multicolumn{3}{|c|}{ b. Natural control method } \\
\hline Safe Period (rhythm method) & $311(86.4)$ & $49(13.6)$ \\
\hline Breast Feeding (amenorrhea method) & $119(33.1)$ & $241(66.9)$ \\
\hline Withdrawal method (coitus interruption) & $315(87.5)$ & $45(12.5)$ \\
\hline \multicolumn{3}{|c|}{ c. Modern methods } \\
\hline \multicolumn{3}{|c|}{ Hormonal } \\
\hline $\begin{array}{l}\text { Combined Oral Contraceptives e.g ordinary } \\
\text { piles, emergency contraceptives }\end{array}$ & $312(86.7)$ & $48(13.3)$ \\
\hline Injectable Contraceptives & $326(90.6)$ & $34(9.4)$ \\
\hline Contraceptives implants, (implanon) & $324(90.0)$ & $36(10.0)$ \\
\hline Contraceptives Ring (nuva ring) & $316(87.8)$ & $44(12.2)$ \\
\hline Skin Patch & $312(86.7)$ & $48(12.5)$ \\
\hline \multicolumn{3}{|c|}{ Intra-uterine contraceptives (IUCDs) } \\
\hline Copper T shaped IUD (paraGard) & $276(83.4)$ & $55(16.6)$ \\
\hline Hormonal IUD (mirena) & $40(12.1)$ & $291(87.9)$ \\
\hline \multicolumn{3}{|c|}{ Barrier method of contraception } \\
\hline Condoms (male and female) & $286(79.4)$ & $74(20.6)$ \\
\hline Cervical caps & $38(10.6)$ & $322(89.4)$ \\
\hline
\end{tabular}

Source: Field Survey, 2018; Values in parenthesis are percentages. 
Level of sensitization on the benefits of birth control measures in the coastal areas

Results in Table 2 revealed that $57.5 \%$ of the respondents were well informed that birth control allows child spacing thereby enhancing women's health and promoting child's growth; $60.8 \%$ got information that it reduces child and maternal mortality by preventing unwanted pregnancies and unsafe abortions; $65.3 \%$ reported that it enables partners enjoy sex more because there is no fear of unwanted pregnancies; $67.2 \%$ knew that it helps to control over population and lessens pressure over limited natural resources; and $81.1 \%$ mentioned that it contributes significantly to women' earning power since they are actively participating in fish processing activities. In addition, 75\% have the information that it reduces poverty by contributing to economy of the family, community and national level; $53.1 \%$ indicated that it reduces women susceptibility to ovarian and cysts cancer; $57.8 \%$ stated that it regulates menstrual flows and reduces menstrual cramps/ pre-menstrual symptoms; $55.3 \%$ said that it reduces the risk of acquiring and transmitting sexually Transmitted Infections (STIs). The implication of these findings is that the fish processors have access to information and they are well informed on the benefits of BCMs. But, the women fish processors are still need to be encouraged to use the BCMs for a better reproductive health and efficient fish processing in the coastal areas; this assertion is on the premise of Nyengidiki \&Allagoa [21] that despite high level of awareness of BCMs, utilization is still at very low ebb in Nigeria. Akinsola et al. (2018) also reported low level of utilization of BCMs in the coastal areas of Lagos State, Nigeria..

Table 2: Sensitization on the benefits of birth control measures in the coastal areas $(n=360)$.

\begin{tabular}{|c|c|c|c|}
\hline Sensitization on the Benefits of Birth Control Measures (BCMs) & $\begin{array}{c}\text { Well } \\
\text { Informed }\end{array}$ & $\begin{array}{l}\text { Partially } \\
\text { Informed }\end{array}$ & $\begin{array}{c}\text { Not } \\
\text { Informed }\end{array}$ \\
\hline $\begin{array}{l}\begin{array}{l}\text { Birth control allows child spacing thereby enhancing women's health and promoting child's } \\
\text { growth }\end{array} \\
\end{array}$ & $207(57.5)$ & 133(36.9) & $20(5.6)$ \\
\hline $\begin{array}{l}\text { It reduces child and maternal mortality by preventing unwanted pregnancies and unsafe } \\
\text { abortions }\end{array}$ & $219(60.8)$ & $128(35.6)$ & $13(3.6)$ \\
\hline It enables partners enjoy sex more because there is no fear of unwanted pregnancies & $235(65.3)$ & $116(32.2)$ & $09(2.5)$ \\
\hline It helps to control over population and lessens pressure over limited natural resources & $242(67.2)$ & $90(25.0)$ & 28(7.8) \\
\hline $\begin{array}{l}\text { It contributes significantly to women' earning power since they are actively participating in fish } \\
\text { processing activities }\end{array}$ & $292(81.1)$ & $56(15.6)$ & $12(3.3)$ \\
\hline It reduces poverty by contributing to economy of the family, community and national level & $270(75.0)$ & $65(18.1)$ & $25(6.9)$ \\
\hline It reduces women susceptibility to ovarian and cysts cancer & 191(53.1) & $145(40.3)$ & $24(6.7)$ \\
\hline It regulates menstrual flows and reduces menstrual cramps/ pre-menstrual symptoms & 208(57.8) & $137(38.0)$ & $15(4.2)$ \\
\hline It reduces the risk of acquiring and transmitting sexually Transmitted Infections (STIs) & $199(55.3)$ & $142(39.4)$ & $19(5.3)$ \\
\hline
\end{tabular}

Source: Field Survey, 2018; Values in parenthesis are percentages.

\section{Sources of information on benefits of birth control measures in the in the coastal areas}

From the results in Table 3, most (87.8\%) of the respondents always got information on the benefits of BCMs through their fellow fish processors; $82.2 \%$ through friends and family; and $63.6 \%$ through radio. This corroborates findings of Omoare et al. [15] and Akinsola et al. (2018) that fellow fish processors friends and family are predominantly source of information in the rural settings. On the other hand, $74.7 \%$ occasionally accessed information through television while $86.7 \%$ never got information on benefits of birth control measures from Agricultural Extension Agents (AEAs). It shows that extension services have not been well-rendered to the women fish processors on issue relating to BCMs. Likewise, television has not been effective in this regard. Health Care Providers (81.1\%) were however reported to be very active in sensitizing the women in the study areas; the fact is that women reproductive health is part of their primary mandate and they are closer to the women especially pregnant women and nursing mothers. This finding is supported by the report of Opoku and Kwaunnunu [22] that health workers are the principal source of information on BCMs. Results further showed that $86.4 \%$ and 89.4 of the respondents did not get information on BCMs through social and print media. Low level of formal education of the women processors could limit their access to information through these channels.

Table 3: Distribution based on Sources of information on BCMs $(n=360)$.

\begin{tabular}{|c|c|c|c|}
\hline Sources of information of BCMs & Always & Occasionally & Never \\
\hline Fellow Fish Processors & $316(87.8)$ & $28(7.8)$ & $16(4.4)$ \\
\hline Friends/relatives & $296(82.2)$ & $55(15.3)$ & $09(2.5)$ \\
\hline Radio & $229(63.6)$ & $115(31.9)$ & $16(4.4)$ \\
\hline Television & $68(18.9)$ & $269(74.7)$ & $23(6.4)$ \\
\hline Agricultural Extension Agents & $23(6.4)$ & $25(6.9)$ & $312(86.7)$ \\
\hline
\end{tabular}




\section{Oceanography \& Fisheries Open access Journal}

\begin{tabular}{|c|c|c|c|}
\hline Health Care Providers & $292(81.1)$ & $68(18.9)$ & $0(0.0)$ \\
\hline Social Media & $15(4.2)$ & $34(9.4)$ & $311(86.4)$ \\
\hline Print Media & $09(2.5)$ & $29(8.6)$ & $322(89.4)$ \\
\hline
\end{tabular}

Source: Field Survey, 2018. Values in parenthesis are in percentages.

\section{Hypothesis testing}

\section{Test of relationship between sources of information and sensitization of BCMs}

Results of chi-square revealed that significant relationship existed between Fellow Fish Processors $\left(\chi^{2}=32.19\right.$, df $=4, \mathrm{p}=$ $0.00)$, friends/relatives $\left(\chi^{2}=29.10, \mathrm{df}=4, \mathrm{p}=0.01\right)$, radio $\left(\chi^{2}\right.$ $=11.09, \mathrm{df}=4, \mathrm{p}=0.03)$, television $\left(\chi^{2}=5.90, \mathrm{df}=4, \mathrm{p}=0.05\right)$, Health Care Providers and sensitization of BCMs at $p<0.05$ level of significance. It is an indication that women fish processors are sensitized by their fellow women, friends and Heath Care Provides. Radio and television also sensitized the women fish processors through series of health programmes, talks and dramas. However, no significant relationship was found between Agricultural Extension Agents $\left(\chi^{2}=0.08, \mathrm{df}=4, \mathrm{p}=0.44\right)$, social media $\left(\chi^{2}=0.18, \mathrm{df}=4, \mathrm{p}=0.09\right)$, print media $\left(\chi^{2}=0.14, \mathrm{df}=4\right.$, $p=0.11$ ) and sensitization of birth control measures at $p<0.05$ level of significance; these channels of communication are not effective in sensitizing the women fish processors on the benefits of BCMs. Since there are significant variables it can be said that sources of information had influence on level of sensitization of birth control measures at $\mathrm{p}<0.05$ level of significance hence, null hypothesis is rejected (Table 4).

Table 4: Relationship between sources of information and sensitization of BCMs.

\begin{tabular}{|c|c|c|c|c|}
\hline Sources of information of BCMs & $\boldsymbol{\chi}^{\mathbf{2}}$ & $\mathbf{d f}$ & p-value & Significant \\
\hline Fellow Fish Processors & 32.19 & 4 & 0 & $\mathrm{~S}$ \\
\hline Friends/relatives & 29.1 & 4 & 0.01 & $\mathrm{~S}$ \\
\hline Radio & 11.09 & 4 & 0.03 & $\mathrm{~S}$ \\
\hline Television & 5.9 & 4 & 0.05 & $\mathrm{~S}$ \\
\hline Agricultural Extension Agents & 0.08 & 4 & 0 & NS \\
\hline Health Care Providers & 34.52 & 4 & 0.09 & NS \\
\hline Social Media & 0.18 & 4 & 0.11 & NS \\
\hline Print Media & 0.14 & 4 & & \\
\hline
\end{tabular}

Source: Field Survey, 2018. S - Significant at $p<0.05$ level of significance.

df - degree of freedom.

\section{Conclusion and Recommendation}

This study concluded that the women fish processors are aware of both traditional and modern methods of birth control measures; they have accessed to information on benefits of BCMs through friends, Health Care Providers, radio and television and these channels have been effective in BCMs sensitization programmes in the study area. Chi-square results indicated that sources of information had influence on level of sensitization of birth control measures. It is hereby recommended that the tempo of sensitization on the benefits of BCMs should be continuous in the coastal areas. Health Experts and stakeholders should utilize social and print media especially now that virtually all people are on social media through series of android and iPhones. Agricultural extension agents are very to the grassroots and therefore should be proactive in educating the women fish processors on BCMs. It is very important that effort should be made to redesign birth control campaign in such a way that it will accommodate all the community leaders to ensure its wide spread, utilization and sustainability. This is necessary to promote rural women reproductive health and to ensure efficient fish processing, happy family and crime-free society.

\section{References}

1. Augustine VU, Mathias GA (2011) Contraceptive Awareness and Practice Among Antenatal Attendees in Uyo, Nigeria. Pan Afr Med J 10: 53.

2. African Development Bank Group (2015) Africa Gender Equality Index 2015 Empowering African Women: An Agenda for Action. Africa, pp. $1-27$.

3. Ugboma MU (2014) Availability and Use of Indigenous Knowledge amongst Rural Women in Nigeria. Chinese Librarianship: An International Electronic Journal 38: 60-67.

4. Enete AA, Amusa TA (2010) Determinants of Women's Contribution to Farming Decisions in Cocoa Based Agroforestry Households of Ekiti State, Nigeria. Field Actions Science Reports. The Journal of Field Actions 4: 1-6.

5. Oyediran WO, Omoare AM, Oladoyinbo OB, Ajagbe BO, Dick TT (2016) Constraints limiting the effective utilization of low-cost fish processing technologies among women in selected fishing communities of Lagos State, Nigeria. Fisheries and Aquaculture Journal 7(4): 1-5.

6. Jacoba U (2014) Social and Economic Benefit of Reliable Contraception. 7. NPC (2010) Population Distribution by Age \& Sex (Vol. IV). Nigeria. 
8. Cleland J, Bernstein S, Ezeh A, Faundes A, Glasier A, et al. (2006) Family Planning: the Unfinished agenda. Lancet 368(9549): 1810-1827.

9. Van Stralen MM, Lechner L, Mudde AN, de Vries H, Bolman C (2010) Determinants of Awareness, Initiation and Maintenance of Physical Activity Among the Over-fifties: a Delphi study. Health Educ Res 25(2): 233-247.

10. National Cancer Institute and National Institutes of Health. Making Health Communication (2002) Programs Work. Md. National Institutes of Health, Bethesda, USA, pp. 2-3.

11. Rogers EM (2003) Diffusion of innovations ( $5^{\text {th }}$ edn), Free Press, New York, USA.

12. Schiavo R (2013) Health Communication: From Theory to Practice. John Wiley \& Sons, USA, pp. 33-43.

13. Ahmed-Adamu ZB (2012) Knowledge, Attitude and Practice of natural family planning among couples in Kaduna metropolis. Published MSc Thesis, Department of Sociology, Ahmadu Bello University, Zaria, Kaduna State, Nigeria, p. 146.

14. Sodiya CI, Oyediran WO (2014) Contributions of Melon Production to Livelihood Sustainability of Rural Farming Households in Oyo State, Nigeria. Journal of Biology, Agriculture and Healthcare 4(12): 8- 18.

15. Omoare, AM, Fakoya EO, Abiona BG, Oyediran WO (2013) Fish Marketing: A Panacea towards sustainable agriculture in Ogun State, Nigeria. World Academy of Science, Engineering and Technology
(WASET). Journal of Biological, Agricultural, Biosystems, Life Science and Engineering 7(7): 270-274.

16. Anaman KA, Okai JOA (2016) Extent of Awareness of Birth Control Methods and Their Use by Women in a Peri-Urban Area of Accra, Ghana. Modern Economy 7(1): 39-54.

17. Sonia $O$ (2015) The Contraceptive pill a Revolution for Woman and Man: Conversation Trust (UK), England.

18. Olugbenga-Bello AI, Abodunrin OL, Adeomi AA (2011) Contraceptive Practices Among Women in Rural Communities in South-Western Nigeria. Global Journal of Medical Research 11(2): 1-8.

19. Ijadunola MY, Abiona TE, Ijadunola KT, Afolabi OT, Esimai OA, et al. (2010) Male Involvement in Family Planning Decision Making in IleIfe, Osun state, Nigeria. Afr J Reprod Health 14(4): 43-50.

20. Senbeto E, Alene GD, Abesto N, Yeneneh H (2005) Prevalence and Associated Risk Factors of Induce Abortion in North West Ethiopia. Ethiop J Health Dev 19(1): 37-44.

21. Nyengidiki TK, Allagoa DO (2011) Rupture of The Gravid Uterus in a Tertiary Health Facility in The Niger Delta Region, of Nigeria: A5 year Review. Niger Med J 52(4): 230-234.

22. Opoku B, Kwaununu F (2011) Knowledge and Practices of Emergency Contraception among Ghanaian Women. Afr J Reprod Health 15(2): 147-152.

\section{Your next submission with Juniper Publishers will reach you the below assets}

- Quality Editorial service

- Swift Peer Review

- Reprints availability

- E-prints Service

- Manuscript Podcast for convenient understanding

- Global attainment for your research

- Manuscript accessibility in different formats

( Pdf, E-pub, Full Text, Audio)

- Unceasing customer service

Track the below URL for one-step submission https://juniperpublishers.com/online-submission.php 